\title{
O REGIME INTERNACIONAL DE ACESSO AOS RECURSOS GENÉTICOS E REPARTIÇÃO DE BENEFÍCIOS (RIABS)
}

THE INTERNATIONAL REGIME ON ACCESS AND BENEFIT-SHARING (IRABS)

\section{Vladimir Garcia Magalhães*}

\begin{abstract}
Resumo:
Este trabalho analisa criticamente o texto da minuta do Regime Internacional de Acesso aos Recursos Genéticos e Repartição de Benefícios (RIABS) ${ }^{1}$ em processo de criação no âmbito da Convenção sobre a Diversidade Biológica (CDB). Esta análise é feita com ênfase nos aspectos deste regime relacionados aos direitos de propriedade intelectual. Primeiramente é feito um histórico do processo de criação deste regime, a seguir analisados os principais conceitos envolvidos que são os conceitos de biodiversidade, biopirataria e propriedade intelectual, e a seguir descritos e analisados o uso de termos, objetivo, âmbito e principais componentes do RIABS em discussão.
\end{abstract}

Palavras-chave: Biodiversidade. Recursos Genéticos. Conhecimentos Tradicionais. Convenção sobre a Diversidade Biológica. Propriedade Intelectual.

\begin{abstract}
:
This paper critically analyzes the draft text of an International Regime on Acess and Benefit-Sharing (IRABS) which has been created in the frame of the Convention on Biological Diversity (CBD). This analysis emphasizes related aspects to intellectual property rights. First an historical review of the regime creation procedure is made, after having analyzed the main concepts which are biodiversity, biopiracy and intellectual property and so described and analyzed the IRABS expressions use, objective, scope and main components.
\end{abstract}

Keywords: Biodiversity. Genetic Resources. Traditional Knowledge. Convention on Biological Diversity. Intellectual Property.

\section{Introdução}

Apesar do caráter pioneiro e extrema pertinência da introdução pela Convenção sobre a Diversidade Biológica (CDB) do dever dos seus países-membros elaborarem legislações visando à repartição justa e eqüitativa dos benefícios decorrentes do uso dos recursos genéticos e conhecimentos tradicionais a eles associados, a sua

\footnotetext{
Advogado e biólogo, mestre e doutor em Direito pela Faculdade de Direito da Universidade de São Paulo e Professor do Programa de Mestrado em Direito da Universidade Católica de Santos.

1 Adotamos neste trabalho a sigla RIABS para evitar o uso de siglas demasiado grandes e devido ao fato da expressão "acesso previamente consentido aos recursos genéticos e conhecimentos tradicionais associados e repartição justa e eqüitativa pelo seu uso" ser conhecido pela sigla em inglês pela sigla ABS (Acess and Benefit Sharing). Assim a sigla RIABS significa "Regime Internacional de ABS" o que é equivalente a expressão "Regime Internacional de Acesso aos Recursos Genéticos e Repartição de Benefícios".
} 
efetiva implementação tem deixado muito a desejar desde a sua adoção, em 1992, durante a Conferência das Nações Unidas sobre Meio Ambiente e Desenvolvimento (ECO 92) na cidade do Rio de Janeiro no Brasil.

Não tanto pela falta de edição destas leis pelos países em desenvolvimento, via de regra fornecedores destes recursos biológicos existentes em sua biodiversidade, mas sim mais pela falta de mecanismos jurídicos e institucionais adequados para um efetivo controle do acesso e repartição de benefícios pelo uso dos recursos genéticos, seus derivados e conhecimentos tradicionais associados pelas empresas de biotecnologia, via de regra pertencentes aos países desenvolvidos e com pouca biodiversidade.

Conseqüentemente, continuam a ocorrer acessos aos recursos genéticos em descumprimento à estas determinações da $\mathrm{CDB}$ e das legislações nacionais, entre elas a brasileira, o que configura a prática de biopirataria. ${ }^{2}$

No sentido de coibir a biopirataria, diversas propostas tem sido feitas pelos países megadiversos. Como a biopirataria procura fornecer matéria-prima para as indústrias de biotecnologia desenvolverem produtos e processos que devem ser patenteados ${ }^{3}$ para garantir a exclusividade do seu uso por estas empresas, algumas destas propostas abrangem alterações no Direito Internacional de Propriedade Intelectual, notadamente os acordos internacionais TRIPS e o Tratado de Cooperação em Matéria de Patentes (PCT) para se incluir entre os requisitos para a concessão de patentes, a exigência de revelação de origem dos recursos genéticos, seus derivados, e conhecimentos tradicionais associados. Deste modo, os países megadiversos e suas comunidades tradicionais teriam um mínimo de informações para tentarem controlar o uso destes recursos e conhecimentos podendo requerer judicialmente nos países-membros do TRIPS e PCT a nulidade de patentes desenvolvidas a partir de recursos e conhecimentos tradicionais obtidos por meio da biopirataria.

Outra interessante proposta, tendo em vista a justiça na relação entre os países e cumprimento das determinações da CDB, é a criação de um Regime Internacional de Acesso aos Recursos Genéticos e Repartição de Benefícios (RIABS).

O Brasil é um dos países com maior sócio-biodiversidade do mundo. Portanto, vítima preferencial da biopirataria. Assim, a discussão jurídica em nosso país sobre um eventual RIABS, e sua estrutura, é estratégica para a economia do Brasil e também para a gestão e preservação da sua sócio-biodiversidade ${ }^{4}$ a medida que uma

\footnotetext{
2 Neste sentido, o recente caso de biopirataria no Brasil relativa ao acesso e uso indevido (sem autorização nem repartição de benefícios) pelas empresas brasileiras Natura, Tawaya e Chemyunion do conhecimento tradicional dos índios Ashaninka - do Estado do Acre - relativo à palmeira conhecida por murmuru para fabricação de cosméticos. Este caso ensejou ação civil pública em 07 de agosto de 2007 pelo Ministério Público Federal. Disponível em: <http://6ccr.pgr.mpf.gov.br/atuacao-do-mpf/acao-civil-publiva/docs_acaocivil-publica/ACP_Comunidade_Ashaninka.pdf >. Acesso em: 18/03/2009.

3 A patente é uma modalidade de propriedade intelectual.

4 Conceituamos sócio-biodiversidade como sendo a diversidade de comunidades indígenas e locais tradicionais
} 
efetiva repartição de benefícios decorrentes do uso comercial dos recursos existentes nesta sócio-biodiversidade pode significar um rendimento, para o Brasil ${ }^{5}$ de bilhões de dólares contribuindo assim inclusive para a diminuição da pobreza em nosso país pelo fato das comunidades indígenas e locais tradicionais integrarem as camadas mais pobres da sociedade brasileira.

Este trabalho tem por objetivo analisar criticamente as propostas de estrutura do RIABS, em discussão no âmbito da $\mathrm{CDB}$, com foco em seus aspectos relacionados à propriedade intelectual. Inicialmente se faz um histórico do processo internacional para a estruturação do RIABS. Depois se analisam os conceitos mais importantes para uma melhor compreensão do RIABS e a seguir uma análise crítica das propostas de estrutura do RIABS com ênfase naquelas relacionadas à propriedade intelectual e os principais pontos em discussão quanto a sua eventual estrutura. Finalmente, são apresentadas as conclusões com sugestões para a estrutura do RIABS.

\section{Conceitos}

\subsection{Biodiversidade}

A biodiversidade é um conceito elaborado por biólogos mas utilizado em diversas normas jurídicas nacionais e internacionais. Deste modo, existem conceitos de biodiversidade técnicos (biológicos) e jurídicos muitas vezes discordantes entre si.

Entre os conceitos biológicos destacamos o conceito do ecólogo Edward O. Wilson, que considera a biodiversidade como sendo:

Toda a variação baseada em hereditariedade em todos os níveis de organização, dos genes existentes em uma simples população local ou espécies, as espécies que compõem toda ou parte de uma comunidade local, e finalmente, as próprias comunidades que compõem a parte viva dos multivariados ecossistemas existentes no mundo. ${ }^{6}$ (grifamos).

juntamente com a diversidade de organismos existentes em determinada área assim como a diversidade genética nas diversas espécies de organismos.

5 Nos termos da Medida Provisória 2.186/01 parte deste rendimento pode pertencer ao Estado brasileiro, nas esferas da União, Estados, Distrito Federal ou Municípios, quando forem utilizados pelas empresas de biotecnologia recursos genéticos, e seus derivados, acessados em unidades de conservação de titularidade destes entes públicos e parte também pode pertencer aos proprietários rurais quando estes recursos forem acessados em suas propriedades. Além disso, parte deste rendimento pode pertencer ainda às comunidades indígenas e locais tradicionais quando forem acessados seus conhecimentos sobre estes recursos genéticos e seus derivados.

6 REAKA-KUDLA, Marjorie L.; WILSON, Don E.; WILSON, Edward O. (Eds.). Biodiversity II: Understanding and Protecting our Biological Resources. Washington, D.C.: Joseph Henry Press, 1997. p. 1. 
Por outro lado, do ponto de vista jurídico, a CDB define a biodiversidade (diversidade biológica) assim:

Diversidade biológica significa a variabilidade de organismos vivos de todas as origens, compreendendo, dentre outros, os ecossistemas terrestres, marinhos e outros ecossistemas aquáticos e os complexos ecológicos de que fazem parte; compreendendo ainda a diversidade dentro de espécies, entre espécies e de ecossistemas. (CDB, art. $\left.2^{\circ}\right)$. (grifamos).

Os ecossistemas tem um componente físico denominado de abiótico que são o solo, água, ar e um componente biótico constituído pelos organismos. O conceito de biodiversidade da CDB abrange a diversidade de ecossistemas como um todo, ou seja, abiótica e o de Wilson somente diversidade da parte viva, ou seja, a parte biótica dos ecossistemas.

Ocorre que, do ponto de vista etimológico, a palavra bio vem do grego e significa vida; logo, biodiversidade significa a diversidade de vida. Assim, o conceito etmologicamente mais correto de biodiversidade é o do Wilson, por incluir somente a parte viva (biótica) dos ecossistemas, e não o da $\mathrm{CDB}$ que inclui também a parte física (abiótica) deles. A denominação etmologicamente mais correta de diversidade de ecossistemas seria ecodiversidade.

\subsection{Biopirataria}

Benjamin conceitua biopirataria como sendo "uma expropriação nãoautorizada, nem compensada, de conhecimentos tradicionais e recursos". ${ }^{7}$

Stevenson conceitua que "biopirataria é o roubo de informação biológica". ${ }^{8}$ (grifamos)

Assim podemos conceituar que biopirataria se constitui em uma expropriação de recursos genéticos e demais recursos biológicos assim como de conhecimentos tradicionais a eles associados, sem autorização dos seus titulares e sem qualquer retribuição financeira ou de outra ordem pelo este uso.

\footnotetext{
No original: "Biopiracy is the unauthorized and uncompensate expropriation of traditional knowledge and resources”. BENJAMIN, Craig, 1997 apud TEJERA, Valentina. Tripping over Property rights: is it possible to reconcile the Convention on Biological Diversity with article 27 of the TRIPs agreement? New England Review, New England, v. 33, 1998-1999. p. 971.

8 No original: "biopiracy is the stealing of biological information". STEVENSON, Gelvina R. Trade secrets: the secret to protecting indigenous ethnobiological (medicinal) knowledge. Journal of International Law and Politics, New York, v. 32, n. 4, 2002. p. 1.122.
} 


\subsection{Propriedade intelectual}

A propriedade intelectual é o produto da atividade intelectual humana nos campos industrial, científico e literário. É um bem imaterial, portanto, que é tutelado pelos direitos de propriedade intelectual. Esses direitos não se aplicam aos objetos materiais nos quais as criações se materializam, mas sim na criação em si mesma.

A propriedade intelectual divide-se em propriedade industrial e em direitos autorais (copyright). As produções literária, artística e científica pertencem à esfera dos direitos autorais. As áreas de perfomances artísticas tais como discos e programas de rádio são usualmente chamadas de direitos conexos aos direitos autorais.

A propriedade industrial abrange as invenções, os desenhos industriais, as marcas e os nomes comerciais. As invenções são protegidas pela patente, que é um documento publicado pelo Estado que descreve uma invenção e também cria um direito de exclusividade para o titular da patente, pelo qual a invenção só pode ser utilizada mediante a sua autorização.

Existe ainda um novo direito de propriedade intelectual sui generis criado posteriormente a estes acima mencionados chamados de direito do obtentor. Este direito confere ao seu titular exclusividade pelo uso de uma nova variedade vegetal ${ }^{9}$ por ele desenvolvida.

A doutrina em geral justifica a necessidade de proteção legal destas criações do intelecto humano principalmente com o argumento de que esta proteção incentiva a criatividade humana, a disseminação e a aplicação dos seus produtos, estimulando um comércio que contribui para o desenvolvimento econômico e social.

Contudo, a indiana Vandana Shiva discorda destes argumentos e faz algumas restrições aos direitos de propriedade intelectual. Esta Autora afirma que a sociedade humana sempre produziu conhecimentos trocados livremente entre as pessoas até o surgimento dos direitos de propriedade intelectual no século XIX, que privatizaram o conhecimento impedindo esta troca livre que ocorria anteriormente. ${ }^{10}$

Outra restrição que ela faz é que os direitos de propriedade intelectual somente são reconhecidos quando têm utilidade industrial e comercial, ou seja, geram lucros, e não quando satisfazem necessidades sociais o que exclui todos os demais setores sociais, como as comunidades tradicionais, que criam inovando e produzindo fora da organização industrial capitalista. Em suas palavras:

\footnotetext{
9 A Convenção UPOV define variedade vegetal como sendo um conjunto de plantas do nível taxonômico mais baixo conhecido (art. $1^{\circ}$,vi). Em outras palavras uma variedade vegetal é uma subdivisão de uma espécie vegetal.

10 SHIVA, Vandana. Biopirataria. Petrópolis: Vozes, 2001. p. 35.
} 
O lucro e a acumulação de capital são os únicos fins da criatividade; o bem social não é mais reconhecido. Sob o controle das corporações, ocorre a "desindustrialização" das produções em pequena escala nos setores informais da sociedade. ${ }^{11}$

Questionando o argumento de que os direitos de propriedade intelectual são necessários para compensar a inventividade e estimulá-la, Shiva aponta estudos de Reich que concluem que não existem evidências concretas de que as patentes, por exemplo, estimulem de fato novas invenções. Elas seriam mais utilizadas para bloquear a entrada de outras empresas no mercado. Um instrumento para a sua monopolização. Cita o exemplo de que após a extensão da proteção do direito de propriedade intelectual às variedades de plantas e o estabelecimento nos tribunais americanos do entendimento de se conceder patentes de organismos, diminuiu consideravelmente o número de empresas independentes de produção de sementes nas últimas décadas. $O$ mercado de sementes estaria se oligopolizando nas mãos de empresas gigantes da área petroquímica e farmacêutica. ${ }^{12}$

\section{Histórico do RIABS}

\subsection{O período de 1992 a 2002}

Apesar de a CDB ter sido adotada em 1992 e ter entrado em força em 1993, somente em 1999 começaram os trabalhos para se tentar efetivar as determinações desta convenção em relação ao acesso previamente consentido e repartição dos beneficios gerados pelo uso dos recursos genéticos, seus derivados, e conhecimentos tradicionais associados $\left(\mathrm{ABS}^{13}\right)$.

O resultado destes trabalhos foram as Diretrizes de Bonn sobre ABS adotadas pela $6^{\text {a }}$ Conferência das Partes em abril de 2002.

As Diretrizes têm por objetivo auxiliar as Partes, governos e outras partes interessadas a desenvolver estratégias para implementar as determinações da CDB relativas ao ABS, através do estabelecimento de medidas legais, administrativas e a negociação de contratos de acesso aos recursos genéticos.

\footnotetext{
${ }_{11}$ SHIVA, Vandana. Biopirataria. Petrópolis: Vozes, 2001. p. 35.
}

12 REICH, Leonard, 1985 apud SHIVA, Vandana. op. cit., p. 35.

13 Optamos por utilizar neste trabalho a sigla ABS correspondente ao termo em inglês "Access and BenefitSharing" ao invés de utilizar a sigla correspondente em português ARB (Acesso e Repartição de Benefícios) pelo fato da sigla ABS ser amplamente utilizada nos textos internacionais e mesmo em muitos artigos em português, enquanto a sigla $\mathrm{ARB}$ não é utilizada, procurando assim facilitar a leitura e compreensão deste artigo assim como a leitura e compreensão de outros artigos nacionais e estrangeiros que tratam do tema "acesso e repartição de benefícios pelo uso de recursos genéticos e conhecimentos tradicionais associados". 
A Conferência Mundial sobre Desenvolvimento Sustentável (CMDS) que ocorreu em setembro, de 2002, em Johanesburg (África do Sul) adotou um Plano de Implementação que em seu parágrafo 44, alínea “o", determina que os países, tendo em mente as Diretrizes de Bonn, negociem no âmbito da CDB um regime internacional de acesso aos recursos genéticos, seus derivados, e conhecimentos tradicionais associados para promover e salvaguardar a repartição justa e eqüitativa dos benefícios resultantes da utilização destes recursos.

O parágrafo 44, alínea " $n$ " deste documento estabelece ainda que para se alcançar os objetivos da CMDS é necessário se realizar ações contínuas para uma ampla implementação das Diretrizes de Bonn sobre o ABS de modo a auxiliar os países a desenvolver medidas políticas, administrativas e legais neste sentido.

\subsection{O Período de 2003 a 2009}

Em razão destas determinações, em março de 2003 o Programa de Trabalho Plurianual para a Conferência das Partes de 2010 (COP-10) considerou necessário organizar uma agenda específica para a questão do RIABS e recomendou ao Grupo de Trabalho Ad-Hoc sobre ABS (GTABS) ${ }^{14}$ da CDB analisar o processo de estruturação, natureza, abrangência, elementos e possíveis modalidades de um RIABS para subsidiar a $7^{\mathrm{a}}$ Conferência das Partes (COP-7).

Em fevereiro de 2004, a COP-7, em Kuala Lumpur, atribuiu ao GTABS a tarefa de elaborar e negociar um regime internacional de acesso e repartição de benefícios em colaboração com o Grupo de Trabalho Ad-Hoc sobre o art. 8(j) da CDB, assegurando a participação de comunidades tradicionais (indígenas e locais), organizações nãogovernamentais, indústrias e também de instituições científicas e acadêmicas.

Esta determinação foi reiterada pela COP-8, realizada em Curitiba, a qual estabeleceu que esta tarefa deveria ser concluída o mais rapidamente possível e antes da COP-10.

Em razão disto, o GTABS realizou seu quinto encontro em Montreal (Canadá) de 8 a 12 de outubro de 2007 e seu sexto encontro em Geneva (Suíça) no período de 21 a 25 de janeiro de 2008, continuando a elaboração e negociação de um regime internacional de ABS (RIABS) em consonância com a Decisão VIII/4 da COP-8.

\footnotetext{
14 Este grupo de trabalho foi criado pela Conferência das Partes em sua quinta reunião (COP-5) em maio de 2000 em Nairóbi no Quênia. Seu objetivo inicial era desenvolver diretrizes para auxiliar as Partes e "stakeholders" (grupos diretamente interessados) a implementar as determinações da CDB relacionadas ao acesso aos recursos genéticos e conhecimentos tradicionais associados e repartição dos benefícios gerados pelo seu uso (ABS).
} 
Na COP-9 realizada em Bonn (Alemanha) em maio de 2008 foram reiteradas, através da Decisão IX/12, as instruções para o CTABS finalizar esta tarefa o mais rapidamente possível, antes da COP-10 a ser realizada no período de 11 a 29 de outubro em Nagóia (Japão), e foi determinado que o grupo de trabalho neste período realizasse três reuniões para negociar e elaborar o RIABS para ser apresentado na COP-10.

Cumprindo estas determinações, no período de 2 a 8 de abril de 2009, o GTABS realizou em Paris o primeiro destes três encontros com participação de uma delegação do Brasil, entre outros países, e setores da sociedade civil, inclusive de comunidades tradicionais, e organizações de setores empresariais da área da biotecnologia.

Assim, pode-se observar que estamos em um momento estratégico para a discussão política e científica do RIABS pois ele poderá ser finalizado em breve, inclusive na própria COP-10, obrigando todos os países membros da CDB a cumprir suas determinações estando, portanto, ainda em tempo para os países megadiversos, e suas comunidades tradicionais, tentarem inserir no texto e estrutura do RIABS os pontos e termos mais importantes para que recebam de fato uma repartição justa e eqüitativa pelo uso dos seus recursos genéticos, seus derivados e conhecimentos tradicionais associados e deste modo se tentar corrigir ao menos em parte a histórica injustiça existente nas relações que os países desenvolvidos, e suas grandes corporações, tem estabelecido em todos estes séculos com os países em desenvolvimento e suas comunidades tradicionais.

\section{A estrutura do RIABS}

Na reunião do GTABS, realizada em Paris em abril de 2009, foram divulgados os resultados de um estudo denominado de "The Economics of Ecosystems and Biodiversity", desenvolvido por Pavan Sukhdev, demonstrando que o valor econômico da biodiversidade mundial, e conhecimentos tradicionais associados, era incrivelmente alto, correspondente à soma do valor da indústria automobilística e o da indústria da informação. ${ }^{15}$

Além disto, nesta reunião foi elaborada uma minuta de RIABS com diversas alternativas de textos e uso de expressões em quase todos os itens para servir de base para discussão na COP-10. Nesta minuta o RIABS ficou estruturado com os seguintes elementos: I- Objetivos; II- Âmbito (objeto); III- Principais Componentes. ${ }^{16}$ Em relação à

\footnotetext{
15 CONVENÇÃO sobre a Diversidade Biológica, Grupo de Trabalho Ad Hoc sobre ABS. Report of the Seventh Meeting of the Ad Hoc Open-Ended Working Group on Access and Benefit-Sharing (UNEP/CBD/WGABS/7/8), Paris: 05 de maio de 2009, p.1. Disponível em: <https://www.cbd.int/doc/meetings/abs/abswg07/official/abswg-07-08-en.pdf>. Acesso em: 18 junho 2009.

16 Id. Ibid., p. 21-56.
} 
sua natureza jurídica já tinha sido acordado em reunião anterior que esta seria discutida na próxima reunião do GTABS. ${ }^{17}$

4.1. O uso dos termos "apropriação indébita", "uso indevido" e "biopirataria"

A maior divergência entre os representantes das partes na elaboração do texto da minuta foi em relação ao objeto do regime e ao uso das expressões, "apropriação indébita", ${ }^{18}$ "uso indevido"19 e "biopirataria". ${ }^{20}$ Nesta minuta fica evidente o esforço em se evitar o uso da expressão "biopirataria" em nosso entender devido ao fato de a "pirataria" internacional ser considerada um crime internacional e as normas para seu combate possuirem a natureza jurídica de jus cogens, ${ }^{21}$ princípio fundamental do Direito Internacional que não pode ser derrogado por nenhum acordo internacional conforme entendimento da Tribunal Internacional Permanente de Justiça (TIJ) ${ }^{22}$ e de outros tribunais internacionais com base na Convenção de Viena de 1969 sobre o Direito dos Tratados que em seus arts. $53^{23}$ e $64^{24}$ estipulou que o ius cogens, também denominado de "normas imperativas de direito internacional geral", anulam qualquer tratado internacional ou dispositivo de seus textos com que entrem em conflito.

O uso da expressão "biopirataria” no texto do RIABS, poderia eventualmente, por se tratar de uma modalidade de pirataria, suscitar litígios em tribunais internacionais relativos às determinações dos acordos internacionais sobre propriedade intelectual, como o TRIPS, ${ }^{25}$ que pudessem favorecer a prática de biopirataria internacional e,

17 CONVENÇÃO sobre a Diversidade Biológica, Grupo de Trabalho Ad Hoc sobre ABS. Report of the Seventh Meeting of the Ad Hoc Open-Ended Working Group on Access and Benefit-Sharing (UNEP/CBD/WGABS/7/8), Paris: 05 de maio de 2009, p.7. Disponível em: $<$ https:/www.cbd.int/doc/meetings/abs/abswg07/official/abswg-07-08-en.pdf>. Acesso em: 18 junho 2009.

18 No original: "misappropriation".

19 No original: "misuse".

20 No original: "biopiracy".

21 Cf. BASSIOUNI, Cherif M. International crimes: Jus Cogens And Obligatio Erga Omnes. Law And Contemporary Problems, v. 59, n. 4, 1996. p.68.

22 Id. Ibid., p.71.

23 “Art. 53 - Tratado em conflito com uma norma imperativa de Direito Internacional Geral (Jus Cogens). É nulo o tratado que, no momento de sua conclusão, conflita com uma norma imperativa de direito internacional geral. Para os fins da presente Convenção, uma norma imperativa de direito internacional geral é uma norma aceita e reconhecida pela comunidade internacional dos Estados no seu conjunto, como norma da qual nenhuma derrogação é permitida e que só pode ser modificada por nova norma de direito internacional geral da mesma natureza".

24 “Art. 64 - Superveniência de uma nova norma imperativa de Direito Internacional Geral (Jus Cogens). Se sobrevier uma nova norma imperativa de direito internacional geral, qualquer tratado existente em conflito com essa norma torna-se nulo e extingue-se.

25 "Agreement on Trade Related Aspects of Intellectual Property Rights (TRIPS)". No vernáculo "Acordo Relativo aos Aspectos do Direito da Propriedade Intelectual Relacionados com o Comércio (ADPIC)”. Este tratado internacional foi celebrado ao final da Rodada do Uruguai do Acordo Geral sobre Tarifas e Comércio (GATT), em 1994, como anexo do tratado internacional que criou a Organização Mundial do Comércio 
conseqüentemente, o risco de anulação de dispositivos destes acordos por tribunais internacionais competentes com o argumento de serem contrários ao jus cogens. Risco este indesejável pelos países industrializados, detentores e desenvolvedores de tecnologia, que são os maiores interessados no direito de propriedade intelectual e principais responsáveis pelo atual texto do TRIPS, administrado pela Organização Mundial do Comércio (OMC), e demais acordos internacionais sobre direitos de propriedade intelectual administrados pela Organização Mundial sobre a Propriedade Intelectual (OMPI) e União Internacional para a Proteção de Obtenções Vegetais (UPOV).

Além das normas de combate à pirataria, também os Direitos Humanos têm natureza de ius cogens, conforme nos ensina Guido Soares. ${ }^{26}$ Ocorre que os conhecimento tradicionais estão na esfera dos direitos humanos, nos termos dos arts. 17 e 27 da Declaração Universal dos Direitos Humanos. Sendo que este entendimento é confirmado pela Resolução 2.200 A de 1996, da Assembléia Geral das Nações Unidas, e a Resolução 2001/7 da Sub-Comissão de Direitos Humanos do ACDH - Alto Comissariado para Direitos Humanos da ONU.

Além disso, em 13 de setembro de 2007, a Assembléia Geral da ONU aprovou a Declaração das Nações Unidas sobre os Direitos dos Povos Indígenas seguindo a recomendação dada pela Resolução 1/2 do Conselho dos Direitos Humanos, de 29 de junho de 2006, que aprovou o seu texto. Esta declaração determina em seu art. 37.1 que os povos indígenas têm o direito de manter, controlar e proteger seus conhecimentos tradicionais assim como a sua propriedade intelectual sobres estes conhecimentos.

Assim, qualquer norma de direito internacional, inclusive sobre propriedade intelectual, que contribuir para violar este direito, seja por ação ou por omissão, são nulas nos termos da Convenção de Viena sobre o Direito dos Tratados (arts. 53 e 64). Se dispositivos do TRIPS ou dos tratados sobre propriedade intelectual administrados pela OMPI ou UPOV forem omissos em coibir a biopirataria tanto dos recursos genéticos e seus derivados quanto dos conhecimentos tradicionais associados, ou ainda se eles contribuírem para esta biopirataria podem eventualmente ser declarados nulos nos Tribunais Internacionais.

\subsection{O uso dos termos "recursos genéticos", "recursos genéticos e seus derivados" e "recursos biológicos"}

Outro aspecto polêmico ao longo do texto da minuta é a expressão para designar o objeto do RIABS. Representantes de alguns países desenvolvidos desejaram

(OMC). O TRIPS estabelece os requisitos que as leis nacionais devem exigir para a concessão de direitos de propriedade intelectual.

26 SOARES, Guido F. S. Curso de direito internacional público. São Paulo: Ed. Atlas, 2002. p. 133. 
utilizar o termo "recursos genéticos", enquanto os representantes dos países em desenvolvimento desejaram utilizar o termo "recursos genéticos e seus derivados" ou então "recursos biológicos". A diferença é que, conforme as definições estabelecidas pela CDB em seu art. $2^{\circ}$, o termo "recursos genéticos" se refere somente aos genes excluindo, em uma interpretação literal, as demais moléculas biológicas de grande valor para a indústria de biotecnologia, enquanto o termo "recursos genéticos e seus derivados" ou "recursos biológicos" englobam os recursos genéticos e as demais moléculas biológicas existentes nos organismos que são sintetizadas a partir das informações contidas nos genes dos organismos ${ }^{27}$ sendo que estas moléculas são mais comumente utilizadas pela indústria de biotecnologia do que os genes.

Evidentemente que para os países detentores de grande biodiversidade o mais interessante é o uso do termo mais abrangente para tutelar os seus recursos naturais de interesse para a indústria biotecnológica, ou seja, o uso do termo "recursos genéticos e seus derivados" 28 ou "recursos biológicos". ${ }^{29}$ Por outro lado, os países desenvolvidos, detentores da maior parte da indústria biotecnológica mundial, desejam o uso da expressão que englobe uma menor parcela possível dos recursos biológicos que utilizam para ter que repartir eventualmente os benefícios gerados somente pelo uso desta pequena parcela dos recursos biológicos. Por isso, evidentemente, preferem a expressão "recursos genéticos" 30 ao invés de "recursos genéticos e seus derivados" ou "recursos biológicos".

\subsection{O uso dos termos "deverá", "deveria" e "poderia"}

Outro ponto de divergência é a escolha do verbo modal em inglês "shall" ("deverá") ou "should" (“deveria") ou "may" ("pode", no sentido de ser opcional, de se ter permissão para determinado ato) no texto da minuta do RIABS para se referir ao cumprimento das determinações do RIABS. O uso do termo "deverá" impõe incondicionalidade do cumprimento do ato prescrito pela norma do RIABS, o uso do

27 Para maiores detalhes sobre a relação entre estes conceitos e sobre o valor econômico dos recursos biológicos para a biotecnologia vide MAGALHÃES, Vladimir Garcia. Propriedade intelectual, biotecnologia e biodiversidade. 2005. Tese (Doutorado) - Faculdade de Direito, Universidade de São Paulo, São Paulo. p. 56-59, p. 93-99 e p. 167-168.

28 Todas as moléculas biológicas de interesse para a indústria de biotecnologia são derivadas dos recursos genéticos,ou seja, dos genes.

29 A CDB em seu art. $2^{\circ}$ conceitua que recursos biológicos "compreende recursos genéticos, organismos ou partes destes, populações, ou qualquer outro componente biótico de ecossistemas, de real ou potencial utilidade ou valor para a humanidade. Assim, o termo "recursos biológicos" abrange os genes e todas as demais moléculas biológicas de interesse para a indústria da biotecnologia. Portanto, o termo "recursos genéticos e seus derivados" significa o mesmo que "recursos biológicos.

30 Os recursos genéticos são os genes, ou seja, as unidade básicas responsáveis pela transmissão das características hereditárias e responsáveis pela sínteses, em todos os organismos vivos, das demais moléculas biológicas. 
termo "deveria" ao contrário indica uma conduta desejada e o termo "pode" indica somente uma possibilidade de conduta mas nenhuma obrigação de adotá-la. Essas são diferenças vitais que determinarão o grau de eficiência do cumprimento do RIABS e, conseqüentemente o grau com que ele cumprirá os seus objetivos. Portanto, outro ponto estratégico da elaboração do texto do RIABS.

\subsection{Objetivo}

A minuta do GTABS estabelece que o objetivo do RIABS é efetivar as determinações dos arts. $8(\mathrm{j})^{31}$ e $15^{32}$ da CDB, havendo sugestões de inclusão do objetivo de implementar efetivamente também os arts. 1, 3, 16 e 19.2 deste diploma internacional. Para tanto, o RIABS deve procurar garantir os 3 objetivos expressos nestes artigos da CDB: o acesso previamente consentido pela autoridade nacional competente, em termos mutuamente acordados, aos recursos genéticos e seus derivados; a repartição justa e eqüitativa dos benefícios comerciais e tecnológicos pelo uso destes recursos biológicos e conhecimentos tradicionais associados; prevenir o uso indevido ou apropriação indébita (biopirataria na realidade) destes recursos; e assegurar, nos países que utilizam estes recursos, o cumprimento do RIABS e das leis nacionais relativas ao ABS que estão em consonância com a CDB, levando-se em conta a Declaração da ONU sobre os Direitos dos Povos Indígenas. ${ }^{33}$

\section{5. Âmbito}

Em relação ao âmbito do RIABS, aparecem na minuta as divergências apontadas anteriormente quanto ao uso das expressões "recursos genéticos", "recursos genéticos e seus derivados" e "recursos biológicos" cabendo à COP-10 fazer a escolha para a elaboração do texto definitivo. Assim, o RIABS se aplicaria a estes recursos, aos benefícios comerciais, dentre outros, gerados pelo uso destes recursos e conhecimentos tradicionais associados, localizados em uma jurisdições nacional, localizados em mais

31 O art.8 (j) determina que as Partes devem, "na medida do possível e conforme o caso", em "conformidade com sua legislação nacional, respeitar, preservar e manter o conhecimento, inovações e práticas das comunidades locais e populações indígenas com estilo de vida tradicionais relevantes à conservação e à utilização sustentável da diversidade biológica e incentivar sua mais ampla aplicação com a aprovação e a participação dos detentores desse conhecimento, inovações e práticas; e encorajar a repartição equitativa dos benefícios oriundos da utilização desse conhecimento, inovações e práticas".

32 Este artigo institui o ABS para o acesso aos recursos genéticos.

33 CONVENÇÃO sobre a Diversidade Biológica, Grupo de Trabalho Ad Hoc sobre ABS. Report of the Seventh Meeting of the Ad Hoc Open-Ended Working Group on Access and Benefit-Sharing (UNEP/CBD/WGABS/7/8), p. 21. 
de uma jurisdição nacional (transfronteiriços) ${ }^{34}$ e espécies migratórias eventualmente encontradas nos territórios das Partes. ${ }^{35}$

O RIABS se aplicaria também a todos os direitos de propriedade intelectual (DPI) associados com pesquisa e tecnologia desenvolvidas a partir dos recursos genéticos, seus derivados e conhecimentos tradicionais associados. ${ }^{36}$

Ficaria excluído do âmbito de aplicação do RIABS os recursos genéticos humanos e os recursos genéticos e seus derivados adquiridos em período anterior a entrada em vigor internacional da CDB, ou em vigor para a Parte, diante do entendimento que obrigações instituídas pelo RIABS não serão aplicadas retroativamente. Ficariam também excluídos do seu âmbito as espécies vegetais listadas no Anexo 1 do Tratado Internacional sobre Recursos Fitogenéticos para a Agricultura, a menos que sejam utilizados para outros fins que não os estabelecidos neste tratado, e também os recursos biológicos marinhos localizados em áreas além dos limites das jurisdições nacionais ou localizados na área do Tratado da Antártida ou ainda na área da Convenção sobre a Conservação dos Recursos Marinhos Vivos da Antártida. Finalmente, estariam ainda excluídas as commodities em comércio. ${ }^{37}$ Finalmente, ficaria também excluída a troca de recursos genéticos e seus derivados ou conhecimentos tradicionais associados entre comunidades tradicionais para o seu próprio uso baseado em práticas costumeiras. ${ }^{38}$

A minuta do RIABS determina ainda que este seja implementado em harmonia com tratados relevantes, incluindo, inter alia, Comissão da Organização Mundial para Alimentação e Agricultura sobre Recursos Genéticos para Alimentação e Agricultura, OMPI e UPOV. Contudo, o texto desta minuta não menciona a OMC nem o TRIPS administrado por ela. Deve-se notar, porém, que esta organização enviou observadores para esta $7^{\text {a }}$ Reunião do GTABS que elaborou esta minuta. ${ }^{39}$

\subsection{Principais componentes}

Os principais componentes do RIABS são: A- Repartição Justa e Eqüitativa; B- Acesso aos Recursos Genéticos e C- Cumprimento.

\footnotetext{
34 Importante porque muitos biomas ocorrem em mais de um país, como o Bioma Amazônia, Bioma Cerrado, Bioma Pantanal e outros biomas brasileiros e de outros continentes.

35 Convenção sobre a Diversidade Biológica, Grupo de Trabalho Ad Hoc sobre ABS, op. cit., p. 21.

36 Id. Ibid., p. 22.

37 Commodity" é um termo em inglês que, como o seu plural commodities, significa mercadoria, porém comumente é utilizado para designar os produtos de base em estado bruto (matérias-primas) como produtos agrícolas, minérios, etc. Infelizmente, diante da pluralidade de significados deste termo, o texto da minuta não conceitua "commodities no comércio", o que seria recomendável que ocorresse".

38 CONVENÇÃO sobre a Diversidade Biológica, Grupo de Trabalho Ad Hoc sobre ABS. cit., p. 22.

39 Id. Ibid., p. 23.
} 
O componente "repartição justa e eqüitativa" abrange diversos tópicos dos quais destacamos: a definição da conexão entre o acesso previamente consentido e a repartição justa e eqüitativa; a definição dos tipos de benefícios (monetários, não-monetários e acesso/transferência de tecnologia) a serem repartidos em termos mutuamente acordados entre o provedor dos recursos genéticos, seus derivados e conhecimentos tradicionais associados, repartição dos resultados e no desenvolvimento das pesquisas com os recursos genéticos e seus derivados; mecanismos para promover a igualdade nas negociações dos termos acordados para o acesso; e aumento de conscientização sobre a importância da repartição de benefícios. ${ }^{40}$

Além disso, o componente da repartição justa e eqüitativa do RIABS abrange medidas para garantir a participação das comunidades tradicionais na negociação dos termos mutuamente acordados de acesso e repartição de benefícios; mecanismos para estimular o uso dos benefícios recebidos na conservação e uso sustentável da biodiversidade e desenvolvimento sócio-econômico; desenvolvimento de padrões internacionais; opções multilaterais quando a origem do recursos genético não for clara ou for transfronteiriça; estabelecimento de fundos para receber os benefícios repartidos em situações transfronteiriças; e desenvolvimento de cláusulas modelo para serem eventualmente utilizadas em contratos para acesso e transferência de recursos genéticos. ${ }^{41}$

O componente "acesso aos recursos genéticos" discute: o reconhecimento da soberania e autoridade das Partes para determinar o acesso; a certeza jurídica, clareza e transparência das normas sobre o acesso; que as normas de acesso sejam não discriminatórias; o estabelecimento de padrões internacionais de acesso para incrementar a harmonia entre as legislações nacionais; a criação de modelos de legislação nacional; a minimização dos custos administrativos e operacionais relativos à concessão do acesso aos recursos genéticos e conhecimentos tradicionais associados; e a simplificação das normas de acesso para fins de pesquisa científica (fins não comerciais). ${ }^{42}$

O componente "cumprimento" do RIABS prevê o desenvolvimento de instrumentos para estimular seu cumprimento, como atividades para aumento de conscientização; discussão e estabelecimento internacional do conceito de "uso impróprio" (misuse) e "apropriação indevida" (misappropriation) não se referindo, porém à biopirataria; identificação de melhores práticas; códigos de conduta para os usuários; e estabelecimento pelas agências de financiamento de pesquisa científica da obrigação que as instituições que recebam seus recursos financeiros cumpram o $\mathrm{ABS}^{43}$

\footnotetext{
40 CONVENÇÃO sobre a Diversidade Biológica, Grupo de Trabalho Ad Hoc sobre ABS. cit., p. 24-31.

${ }^{41}$ Id. Ibid., p. 31-36.

42 Id. Ibid., p. 36-43.

43 Id. Ibid., p. 43-46.
} 
Prevê também o desenvolvimento de instrumentos para seu monitoramento como: mecanismos de troca de informações; certificado internacionalmente reconhecido emitido pela autoridade competente para autorizar o acesso; sistemas de monitoramento para detectar descumprimento dos contratos de acesso e repartição de benefícios e detectar também a "apropriação indébita" dos recursos genéticos; exigência de revelação de origem nas solicitações de concessão de direito de propriedade intelectual; e identificação de pontos para controle de eventuais descumprimentos. ${ }^{44}$

Prevê ainda instrumentos para reforçar o cumprimento do RIABS como: a adoção de medidas para garantir o acesso à justiça; o estabelecimento de mecanismo para solução de conflitos envolvendo Estados, comunidades tradicionais, ONGs, e outros provedores e usuários dos recursos genéticos e conhecimentos tradicionais associados; a execução de decisões arbitrais nas diferentes jurisdições; e o estabelecimento de medidas corretivas e sanções para os casos de seu descumprimento. ${ }^{45}$

Finalmente, o RIABS prevê o estabelecimento de medidas para garantir sua conformidade com costumes e sistemas de proteção dos conhecimentos das comunidades tradicionais. $^{46}$

\subsection{A propriedade intelectual}

Pelo fato dos recursos genéticos, seus derivados e conhecimentos tradicionais associados serem utilizados pela indústria de biotecnologia para o desenvolvimento de produtos e processos passíveis de serem objetos de direitos de propriedade intelectual, o RIABS trata da conexão do ABS com estes direitos.

No componente "repartição justa e eqüitativa", a propriedade conjunta de direitos de propriedade intelectual pelos provedores dos recursos genéticos, seus derivados e conhecimentos tradicionais associados e os usuários destes recursos é uma das formas propostas para a repartição não monetária de benefícios. ${ }^{47}$

Ainda neste componente, a repartição dos resultados e participação no desenvolvimento das pesquisas com os recursos genéticos e seus derivados abrangeria o acesso e transferência de tecnologia protegida por patentes ou outra forma de direito de propriedade intelectual. $\mathrm{O}$ aumento de conscientização é considerado no texto da minuta como instrumento de repartição de benefícios, e abrange a divulgação do RIABS

\footnotetext{
${ }_{44}$ CONVENÇÃO sobre a Diversidade Biológica, Grupo de Trabalho Ad Hoc sobre ABS. cit., p. 46-51.

45 Id. Ibid., p.52-55.

46 Id. Ibid., p. 55-56.

47 Id. Ibid., p. 28.
} 
e a promoção de uma melhor compreensão pelo público dos conceitos de apropriação indébita e uso impróprio. ${ }^{48}$

Finalmente, em relação ao desenvolvimento de padrões internacionais a minuta do RIABS afirma que a definição de "repartição justa e eqüitativa" não é exaustiva e deverá, ou deveria, incluir entre seus elementos básicos o respeito aos sistemas legais e de valores existentes nas diferentes fronteiras culturais, incluindo as normas consuetudinárias (costumes), práticas e sistemas de propriedade intelectual indígenas. ${ }^{49}$

Em relação ao componente do RIABS “acesso aos recursos genéticos" as Partes devem garantir a certeza jurídica, clareza e transparência das normas sobre o acesso facilitando que este ocorra, inclusive por não impor qualquer tipo de restrições contrárias aos objetivos da CDB. O acesso somente pode ser negado se o acesso for solicitado para uso prejudicial ao meio-ambiente. A noção de uso de recursos genéticos e seus derivados deverá, ou deveria, ser entendida como incluindo terceiras partes sendo que os países de origem destes recursos tem a autoridade para definir quando esta restrição de uso dos recursos genéticos através de patentes ou outros direitos de propriedade intelectual é ambientalmente segura e quando esta restrição impacta negativamente a conservação e uso sustentável da biodiversidade. ${ }^{50}$

Em relação aos instrumentos de monitoramento do cumprimento do RIABS foi sugerido a determinação de que as Partes deverão, ou deveriam, estabelecer pontos de controle para o uso comercial o que deverá, ou deveria, incluir os órgãos públicos responsáveis pela concessão de direitos de propriedade intelectual. ${ }^{51}$

Foi sugerido na minuta também, no âmbito do RIABS, a criação de um "certificado internacional de origem" do recurso genético, seus derivados e conhecimentos tradicionais associados a ser exigido como requisito para a concessão de patentes, ou outros direitos de propriedade intelectual, sobre os produtos e processos biotecnológicos desenvolvidos a partir destes recursos e conhecimentos. Contudo, diversos países desenvolvidos se manifestaram contrários a isto. ${ }^{52}$

Em relação ainda ao requisito de revelação de origem dos recursos genéticos, seus derivados e conhecimentos tradicionais associados, uma opção de texto da minuta determina que solicitações de patentes, ou direitos de propriedade intelectual em geral, cujo objeto seja diretamente baseado em recursos genéticos, seus derivados e conhecimentos tradicionais associados, deverão, ou deveriam, ou poderiam revelar o país de origem destes recursos assim como apresentar também evidências de que estes recursos

\footnotetext{
48 CONVENÇÃO sobre a Diversidade Biológica, Grupo de Trabalho Ad Hoc sobre ABS. cit., p.29.

49 Id. Ibid., p. 33.

$50 \quad$ Id. Ibid., p. 39.

51 Id. Ibid., p. 47-50.

52 Id. Ibid.
} 
tenham sido obtidos através de consentimento prévio fundamentado de acesso, termos mutuamente acordados e repartição de benefícios nos termos da legislação nacional do país provedor destes recursos e de acordo com as determinações da CDB. ${ }^{53}$

Além disso, cada Parte deverá, deveria ou pode estabelecer medidas administrativas, civis e/ou criminais para o ocultamento de informações relevantes e fonecimento de informações falsas para as autoridades nacionais devendo também garantir que as autoridades administrativas e/ou judiciárias tenham a autoridade para evitar posterior processamento de uma solicitação de direito de propriedade intelectual ou ainda revogar ou anular este direito quando o solicitante deste direito de propriedade intelectual não cumprir as obrigações de fazer o acesso aos recursos genéticos, de modo previamente informado ou não fizer a repartição de benefícios. A prova do cumprimento destas obrigações deverá, deveria ou pode ser feita através de um certificado de cumprimento da legislação nacional e dos requisitos relativos ao acesso previamente informado e repartição de benefícios (ABS). ${ }^{54}$

Por outro lado, para garantir o cumprimento do RIABS, as Partes devem ou deveriam estabelecer pontos de controle como os escritórios responsáveis pela concessão de direitos de propriedade intelectual, entidades de pesquisa, etc., criando mecanismos como o uso de certificados nacionais ou internacionais do cumprimento do ABS, para prevenir a "apropriação indébita" de recursos genéticos, seus derivados e conhecimentos tradicionais associados. ${ }^{55}$

Em relação às sanções e medidas corretivas, a minuta de RIABS determina que elas deverão ou deveriam ser criadas pelas legislações nacionais e que precisam incluir a possibilidade de anulação do direito de propriedade intelectual obtido a partir do acesso a recursos genéticos em desacordo com a CDB..$^{56}$

\section{Conclusões}

É necessário, para uma maior probabilidade de implementação de fato das determinações da $\mathrm{CDB}$ relativas ao ABS e das determinações da Cúpula Mundial sobre Desenvolvimento Sustentável, de 2002, que o texto definitivo do RIABS utilize os termos "biopirataria", "recursos genéticos" ou, preferencialmente o termo "recursos biológicos". Do mesmo modo, é necessário o uso do termo "deverá" ao invés de "deveria” ou "pode" para as obrigações essenciais para que de fato o ABS seja implementado mundialmente.

\footnotetext{
53 CONVENÇÃO sobre a Diversidade Biológica, Grupo de Trabalho Ad Hoc sobre ABS. cit., p. 51.

54 Id. Ibid.

55 Id. Ibid.

56 Id. Ibid., p. 55.
} 
Neste mesmo sentido, é igualmente necessário que a estrutura do RIABS inclua um sistema de certificação nacional e internacional relativo à origem dos recursos biológicos e conhecimentos tradicionais associados assim como cumprimento do ABS.

Do mesmo modo, à medida que os direitos de propriedade intelectual são utilizados para garantir os lucros gerados pela biopirataria, por concederem direito de exclusividade sobre produtos e processos desenvolvidos pela indústria de biotecnologia com base nos recursos biológicos e conhecimentos tradicionais associados dos países megadiversos em desenvolvimento, é imprescindível que este sistema se articule com o RIABS de modo que esta concessão seja condicionada às determinações da CDB relativas ao ABS.

Finalmente, entendemos que sem esta articulação não-somente permanecerão sem efetividade as determinações da $\mathrm{CDB}$ relativas ao $\mathrm{ABS}$ e mesmo à conservação da biodiversidade, como também as determinações da Conferência Mundial sobre o Desenvolvimento Sustentável e mesmo os Objetivos do Milenium estabelecidos pela ONU no que se refere à diminuição da pobreza nos países em desenvolvimento. Impossibilitando assim a implementação efetiva do desenvolvimento sustentável, tão alardeado pelos países desenvolvidos, assim como uma mudança de paradigma nas relações entre os países desenvolvidos e em desenvolvimento para que a histórica desigualdade destas relações seja substituída pelo estabelecimento de relações mais justas e eqüitativas.

São Paulo, dezembro de 2009.

\section{Referências}

BASSIOUNI, Cherif M. International crimes: jus cogens and obligatio erga omnes. Law And Contemporary Problems, v. 59, n. 4, p. 63-74, 1996.

CONVENÇÃO SOBRE A DIVERSIDADE BIOLÓGICA, GRUPO DE TRABALHO AD HOC SOBRE ABS. Report of the seventh meeting of the ad hoc open-ended working group on access and benefit-sharing (UNEP/CBD/WG-ABS/7/8). Paris, 05 de maio de 2009. Disponível em: <https:// www.cbd.int/doc/meetings/abs/abswg-07/official/abswg-07-08-en.pdf $>$. Acesso em: 18 junho 2009.

MAGAlHÃES, Vladimir Garcia. Propriedade intelectual, biotecnologia e biodiversidade. 2005. Tese (Doutorado) - Faculdade de Direito, Universidade de São Paulo, São Paulo.

REAKA-KUDLA, Marjorie L.; WILSON, Don E.; WILSON, Edward O. (Eds.). Biodiversity II: understanding and protecting our biological resources. Washington, D.C.: Joseph Henry Press, 1997.

SHIVA, Vandana. Biopirataria. Petrópolis: Vozes, 2001. 
SOARES, Guido F. S. Curso de direito internacional público. São Paulo: Ed. Atlas, 2002.

STEVENSON, Gelvina R. Trade secrets: the secret to protecting indigenous ethnobiological (medicinal) knowledge. Journal of International Law and Politics, New York, v. 32, n. 4, p. 1.119$1.174,2002$.

TEJERA, Valentina. Tripping over property rights: is it possible to reconcile the Convention on Biological Diversity with article 27 of the TRIPs agreement? New England Review, New England, v. 33, 1998-1999. 